\title{
Selection for wide temperature adaptation in Chrysanthemum morifolium (Ramat.) Hemsl.
}

\section{J. de Jong}

Institute for Horticultural Plant Breeding (IVT), Wageningen, the Netherlands

Key words: chrysanthemum, Chrysanthemum morifolium, temperature, flowering, breeding

\section{Summary}

In chrysanthemums the same cultivar is grown all the year round in glasshouses and needs to be adapted to low winter and high summer temperatures. As initial selection in a segregating population takes place at one temperature only, the breeder is faced with the problem how best to identify the plants that perform well over the range of temperatures.

Rooted cuttings of commercial cultivars were grown to flowering at five temperatures and the number of short days to flowering was recorded. The optimum temperature for rapid flowering varied between cultivars. The number of days to flowering at the optimum temperature was not related to the delay in flowering caused by either high or low temperature. In many cultivars the delay in flowering at low temperature was accompanied by a similar delay at high temperature. It was concluded that for the character 'time to flowering' genotypes should preferably be selected at low temperatures. If low temperature cannot be realized, only rapidly flowering genotypes should be selected.

\section{Introduction}

Chrysanthemums for cut flower production are grown all the year round in heated glasshouses in the Netherlands. Plants are grown from cuttings that are kept in long days for vegetative development. To induce flowering short days are imposed. Garner \& Allard (1920) showed that temperature is the most important modifying environmental factor in the flowering response of daylight-sensitive plants. Post (1947) found this to be true for chrysanthemums. In his experiments Cathey (1954a) demonstrated that considerable differences exist between chrysanthemum cultivars in their response to temperature. With $15.7^{\circ} \mathrm{C}$ as the base temperature, at which all varieties tested flowered earliest, he introduced the following classification:

- cultivars of the thermozero group which flower under a wide temperature range, with a delay when the temperature is higher or lower than $15.7^{\circ} \mathrm{C}$;

- thermonegative cultivars of which flowering is more severely inhibited at high than at low temperatures; 
- thermopositive cultivars of which flowering is more inhibited at low than at high temperatures.

Night temperatures in Dutch glasshouses are maintained at a minimum of 16$17^{\circ} \mathrm{C}$. In summer the temperature under the blackcloth may rise to $30^{\circ} \mathrm{C}$ and higher. Year-round cultivars therefore need to be adapted to a wide temperature range. Recently interest has been expressed for production at lower night temperatures to save fuel and improve the quality of the winter crop (van der Hoeven \& Vijverberg, 1977). This will require cultivars that will flower in time under an even wider range of temperatures. This means a further challenge for the chrysanthemum breeder.

To determine the modifying effect of temperature on the time to flowering in short days, genotypes should be tested under a series of temperatures. Testing at several temperature regimes is feasible only with a limited number of genotypes in the advanced stages of a breeding programme. In earlier stages, where large numbers of plants with only one or a few individuals per genotype can be compared, testing in one environment is the only practical possibility. This severely restricts information in an early stage on the effect of temperature on flowering time. The aim of the experiments described in this paper was to investigate whether it is possible to select genotypes adapted to a wide range of temperatures at one temperature. The experiments are part of a series of trials aimed at establishing light and temperature conditions in which superior genotypes can best be recognized.

\section{Materials and methods}

The experiments were carried out with a series of commercial cultivars commonly grown in the Netherlands. Rooted cuttings, obtained from a commercial propagator, were potted in 12-cm black plastic pots containing ready-made potting soil (Trio 17) and distributed over five temperatures in the IVT phytotron glasshouses. Long photoperiods were given by interrupting the night (night break) from $23 \mathrm{~h} 00$ to $03 \mathrm{~h} 00$ with $0.5-0.7 \mathrm{~W} / \mathrm{m}^{2}$ incandescent light as measured at the top of the plants. Further experimental details are presented in Table 1.

Natural short days were effected by terminating the night break on the dates mentioned in table 1. To assure uninterrupted nights of at least 15 hours (short days) a curtain was drawn around the plants of Experiments 2 and 3. Temperature measurements during some nights showed that the temperatures realized at plant height in Experiment 2 differed from the preset values of 14, 17, 20, 23 and $26{ }^{\circ} \mathrm{C}$. In Experiments 1 and 3 the planned temperatures were realized. The actual day and night temperatures are presented in Table 1. As night temperature is more critical than day temperature (Cathey, 1954b), the results obtained will be related to the night temperature.

Additional light supplied by high pressure mercury vapour lamps (Philips HPL-N $400 \mathrm{~W}$ ) during $8 \mathrm{~h}$, added $18 \mathrm{~W} / \mathrm{m}^{2}$ to the top of the plants in Experiment 3 . After the flower buds became visible to the naked eye plants in this experiment were grouped according to size as plant height differences resulted in large differences 
J. DE JONG

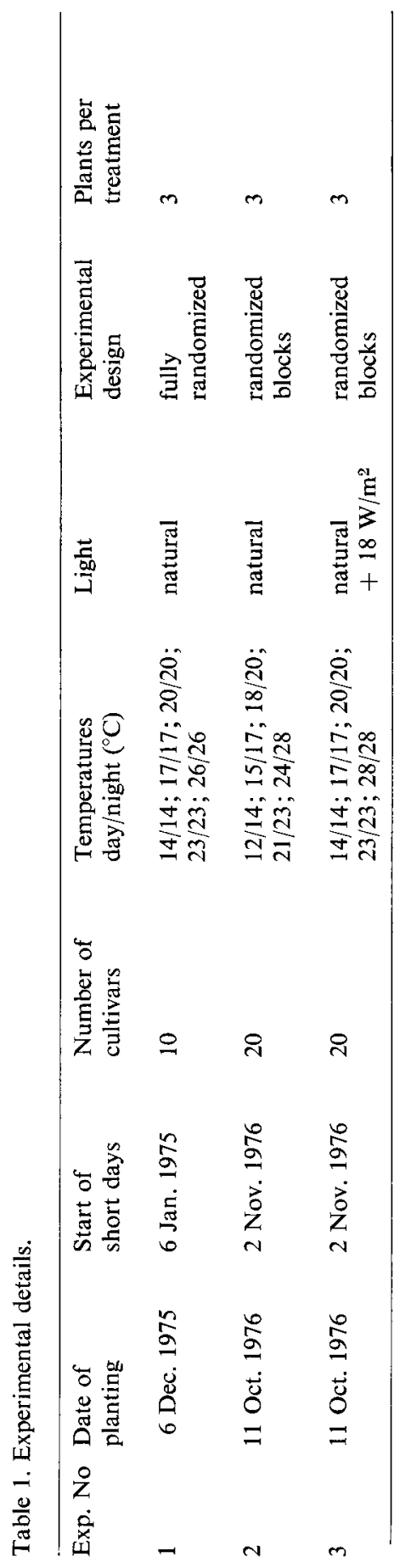


in illumination. The lamps above the plants in Experiment 3 were adjusted accordingly.

Plants were harvested when the outer whorl of ray petals was fully developed. Data from cultivars that budded prematurely, due to floral induction by ageing of the meristem, and not as a result of short day treatments (Cockshull, 1976) were removed from the experiment. Results are expressed as the number of short days to flowering.

\section{Results and discussion}

\section{Optimum temperature}

From Tables 2, 3 and 4 it appears that the optimum night temperature for rapid flowering is between 17 and $21^{\circ} \mathrm{C}$. The optimum temperature differs between experiments which, in view of the difficulties met in obtaining the required temperatures, may well be due to temperature deviations. Cultivars should therefore only be compared within experiments.

The time to flowering at the various temperatures could accurately $(P \leqslant 0.05)$ be described by a parabola for 21 out of 23 cultivars (totalled over all experiments) that flowered at all temperatures and with these curves the precise optimum temperatures were determined. It varied with cultivars. Cultivars with a low temperature optimum are 'Helen' and 'Rosa Spin'. 'Japanerin' and 'Elegance', for which no parabola could be constructed, also seem to have a low optimum temperature. 'Memento' has a high optimum temperature.

The temperature optima found here are higher than the $15.7^{\circ} \mathrm{C}$ reported by Cathey (1969). Ithaca where Cathey did his experiments is on $43^{\circ}$ latitude while

Table 2. The number of short days to flowering of 10 cultivars of chrysanthemum grown under natural winter light conditions at 5 temperatures (Experiment 1).

\begin{tabular}{|c|c|c|c|c|c|c|c|}
\hline \multirow{2}{*}{\multicolumn{2}{|c|}{ Cultivar }} & \multicolumn{5}{|c|}{ Night temperature $\left({ }^{\circ} \mathrm{C}\right)^{2}$} & \multirow{2}{*}{$\begin{array}{l}\text { Calculated optimum } \\
\text { night temperature }\left({ }^{\circ} \mathrm{C}\right)\end{array}$} \\
\hline & & 14 & 17 & 20 & 23 & 26 & \\
\hline$a$ & Bonnie Jean & $82^{1}$ & 68 & 65 & 73 & $94^{1}$ & 19.2 \\
\hline b & Cream Beauty & $110^{I}$ & 71 & 71 & 74 & $*$ & \\
\hline $\mathrm{c}$ & Early Yellow & 64 & 59 & 59 & 62 & 77 & 18.6 \\
\hline d & Golden Horim & $87^{1}$ & 71 & 65 & 69 & $103^{1}$ & 19.4 \\
\hline e & Japanerin & $*$ & $87^{1}$ & $102^{1}$ & $*$ & $*$ & \\
\hline $\mathrm{f}$ & Pink Marble & 75 & 64 & 63 & 67 & 87 & 19.2 \\
\hline $\mathrm{g}$ & Pink Star & 78 & 62 & 64 & 69 & $92^{1}$ & 19.1 \\
\hline h & Star Stream & $105^{1}$ & $76^{1}$ & 69 & 81 & $105^{1}$ & 19.9 \\
\hline i & Super Yellow & 73 & 63 & 61 & 65 & 86 & 19.1 \\
\hline j & Westland $19 \mathrm{Nu}$ & 82 & 63 & 60 & 61 & 76 & 20.4 \\
\hline
\end{tabular}

1 Leafy flower sprays.

2 Figures in italics indicate the observed optimum temperature.

* No flowering within 120 days. 
Table 3. The number of short days to flowering of 20 cultivars of chrysanthemum grown at 5 temperatures under natural winter-light conditions (Experiment 2).

\begin{tabular}{|c|c|c|c|c|c|c|}
\hline \multirow[t]{2}{*}{ Cultivar } & \multicolumn{5}{|c|}{ Night temperature $\left({ }^{\circ} \mathrm{C}\right)^{1}$} & \multirow{2}{*}{$\begin{array}{l}\text { Calculated optimum } \\
\text { night temperature }\left({ }^{\circ} \mathrm{C}\right)\end{array}$} \\
\hline & 12 & 15 & 18 & 21 & 24 & \\
\hline 1 Dark Flamenco & 94 & 69 & 58 & 66 & 78 & 18.8 \\
\hline 2 Dark Illini Springtime & $*$ & 82 & 78 & 84 & * & \\
\hline 3 Elegance & $*$ & 88 & 120 & $*$ & $*$ & \\
\hline 4 Garland & 96 & 67 & 57 & 60 & 80 & 18.7 \\
\hline 5 Geisha & $*$ & 78 & 74 & 105 & $*$ & \\
\hline 6 Helen & 85 & 60 & 59 & 75 & 104 & 16.8 \\
\hline 7 Japanerin & * & 98 & $*$ & $*$ & $*$ & \\
\hline 8 Kingpin & 104 & 80 & 77 & 87 & $*$ & \\
\hline 9 Memento & * & 76 & 62 & 55 & 81 & \\
\hline 10 Milonka & * & 68 & 63 & 77 & 97 & \\
\hline 11 Neptune & 91 & 69 & 57 & 63 & 80 & 18.6 \\
\hline 12 Nina & 107 & 67 & 60 & 65 & 96 & 18.0 \\
\hline 13 Polaris & $*$ & 81 & 66 & 75 & $*$ & \\
\hline 14 Pride & * & 65 & 53 & 58 & 71 & \\
\hline 15 Red Galaxy & * & 92 & 87 & 89 & * & \\
\hline 16 Red Nero & 102 & 70 & 68 & 74 & 102 & 17.9 \\
\hline 17 Rosa Spin & 94 & 63 & 64 & 70 & 90 & \\
\hline 18 Souvenir & 103 & 63 & 61 & 65 & 107 & 17.9 \\
\hline 19 Super White & * & 68 & 63 & 67 & 90 & \\
\hline 20 Westland $19 \mathrm{Nu}$ & 89 & 60 & 58 & 63 & 83 & 18.2 \\
\hline
\end{tabular}

${ }^{1}$ Figures in italics indicate the observed minimum temperature.

* No flowering within 120 days.

Table 4. The number of short days to flowering of 20 cultivars grown at 5 temperatures under natural winter-light conditions supplemented with $18 \mathrm{~W} / \mathrm{m}^{2}$ each day for $8 \mathrm{~h}$ (Experiment 3 ).

\begin{tabular}{|c|c|c|c|c|c|c|}
\hline \multirow[t]{2}{*}{ Cultivar } & \multicolumn{5}{|c|}{ Night temperature $\left({ }^{\circ} \mathrm{C}\right)^{1}$} & \multirow{2}{*}{$\begin{array}{l}\text { Calculated optimum } \\
\text { night temperature }\left({ }^{\circ} \mathrm{C}\right)\end{array}$} \\
\hline & 14 & 17 & 20 & 23 & 28 & \\
\hline 1 Dark Flamenco & 71 & 57 & 58 & 65 & 98 & 19.1 \\
\hline 2 Dark Illini Springtime & $*$ & 70 & 82 & 86 & $*$ & \\
\hline 3 Elegance & 98 & 81 & * & * & * & \\
\hline 4 Garland & 74 & 58 & 59 & 67 & 85 & 19.7 \\
\hline 5 Geisha & 96 & 63 & 79 & 85 & $*$ & \\
\hline 6 Helen & 71 & 54 & 73 & 87 & * & \\
\hline 7 Japanerin & 102 & 84 & * & * & * & \\
\hline 8 Kingpin & 85 & 73 & 82 & 89 & * & \\
\hline 9 Memento & 96 & 68 & 59 & 65 & 96 & 20.9 \\
\hline 10 Milonka & 80 & 56 & 66 & 76 & $*$ & \\
\hline 11 Neptune & 74 & 60 & $?$ & 66 & 94 & 19.4 \\
\hline 12 Nina & 72 & 56 & 60 & 64 & $*$ & \\
\hline 13 Polaris & 81 & 57 & 63 & 77 & $*$ & \\
\hline 14 Pride & 94 & 56 & 61 & 65 & 93 & \\
\hline 15 Red Galaxy & $*$ & 82 & 85 & 92 & $*$ & \\
\hline 16 Red Nero & 76 & 59 & 67 & 73 & $*$ & \\
\hline 17 Rosa Spin & 71 & 58 & 64 & 73 & 105 & 18.2 \\
\hline 18 Souvenir & 77 & 57 & 66 & 75 & $*$ & \\
\hline 19 Super White & 90 & 61 & 64 & 68 & 119 & 19.7 \\
\hline 20 Westland $19 \mathrm{Nu}$ & 74 & 53 & 58 & 61 & 108 & 19.3 \\
\hline
\end{tabular}

1 Figures in italics indicate the observed optimum temperature.

* No flowering within 120 days. 
the Netherlands are on $52^{\circ}$ and consequently, receives much less light in winter. The effect this may have on the optimum temperature is presently being investigated.

\section{Low temperature adaptation}

The time required for flowering (response time) at low temperature can be considered the sum of the time required to flower at the optimum temperature and the temperature-caused delay in flowering. These two components are presented in Fig. 1 to 3. If, for instance, flowering within 74 days at $14{ }^{\circ} \mathrm{C}$ (Fig. 1 and 3) or
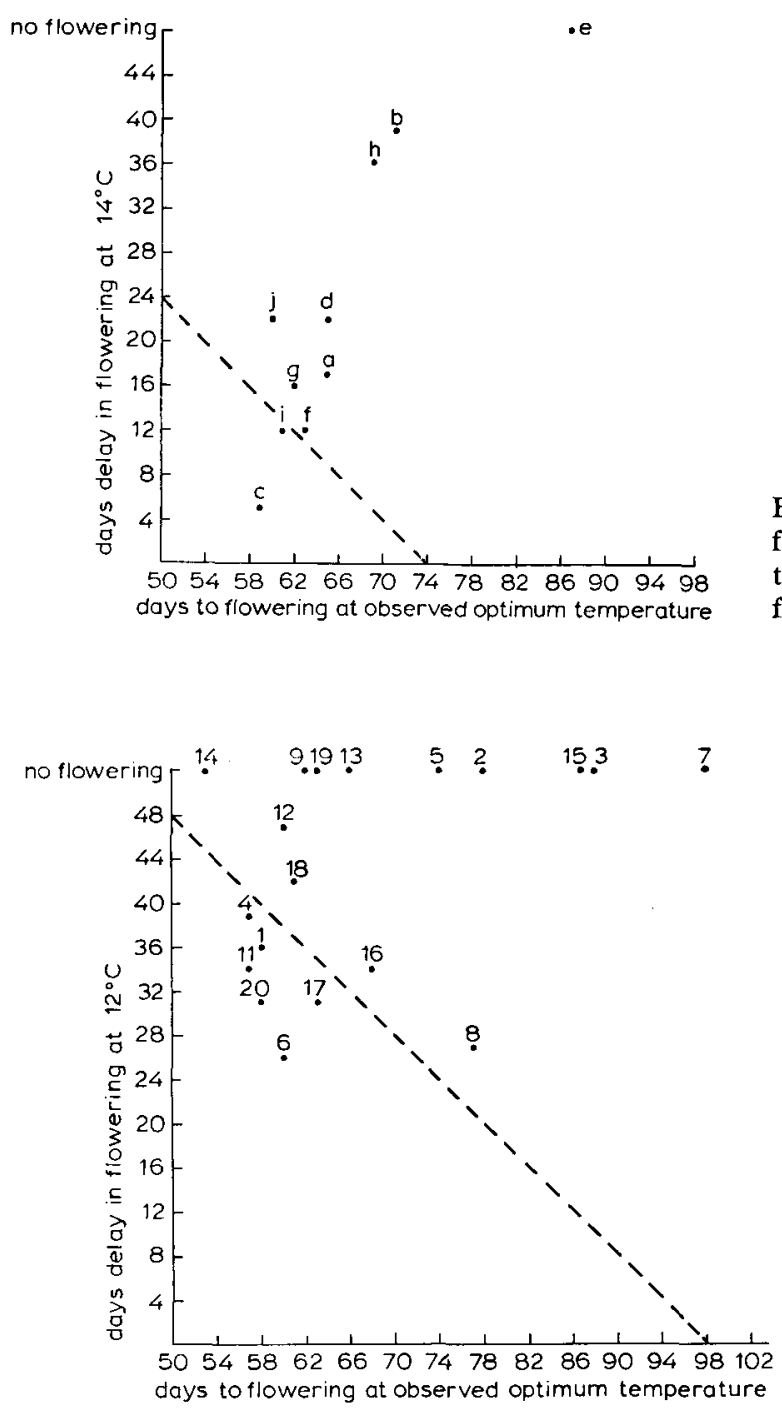

Fig. 1. The relation between days to flowering at the optimum temperature and the delay in days caused by flowering at $14^{\circ} \mathrm{C}$ (Exp. 1, Table 2).
Fig. 2. The relation between days to flowering at the optimum temperature and the delay in days by flowering at $12^{\circ} \mathrm{C}$ in the winter under natural light (Exp. 2, Table 3). 


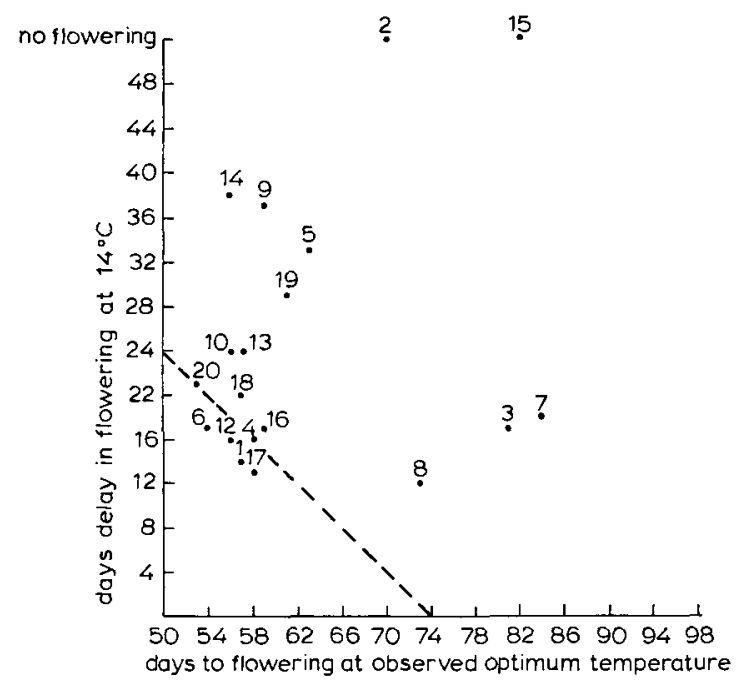

Fig. 3. The relation between days to flowering at the optimum temperature and the delay in flowering at $14{ }^{\circ} \mathrm{C}$ in the winter at natural light intensity supplemented with $18 \mathrm{~W} / \mathrm{m}^{2}$ for 8 hours (Exp. 3, Table 4).

within 98 days at $12{ }^{\circ} \mathrm{C}$ (Fig. 2) is required only cultivars respresented by points below the dotted lines are acceptable.

It is concluded that there is no relation between the time taken to flowering at the optimum temperature and the delay caused by a lower temperature. Cultivars with a short response time at the optimum temperature may thus show a small or an excessively large low temperature delay. As rapid flowering at the optimum temperature does not guarantee rapid flowering at lower temperatures, seedlings intended for year round production should preferably be selected at the lowest winter temperature in which they would be grown ultimately. Seedlings selected for rapid flowering at low, sub-optimal temperature will then flower even faster at higher, optimal temperatures. Nevertheless, in summer when low temperatures cannot be reached, it is advisable to select the faster-flowering plants. This increases the proportion of genotypes that will flower within a commercially acceptable period at low temperatures because the shorter the response time at the optimum temperature, the longer the low temperature delay that can be allowed.

\section{Wide temperature adaptation}

The temperature response curves of all cultivars show an optimum temperature and a delay in flowering at both higher and lower temperatures. If a delay in flowering at high temperature is accompanied by a similar delay at low temperature the response curve will be symmetric and can be described as a parabola. This could be done for 21 out of 23 cultivars (totalled over all experiments) that flowered at all temperatures (see 'Optimum temperature'). Those cultivars represent the thermozero group of cultivars described by Cathey (1954). Within this group there are large differences between cultivars, ranging from the relatively temperature-insensitive cultivar 'Early Yellow' to the very temperature-sensitive cultivar 'Star Stream'.

In the cultivars that flowered at 3 or 4 temperatures only, the complete absence 


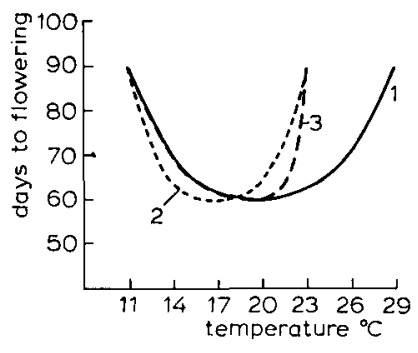

Fig. 4. Three types of responses of chrysanthemums to temperature

1) A symmetric response curve with a normal optimum temperature.

2) A symmetric response curve with a low optimum temperature such as 'Helen'.

3) A skewed response curve with a normal optimum temperature.

of flowering (no flowers within 120 short days) at low temperature is often accompanied by the absence of or delay in flowering at high temperatures. This also points towards a relation between the response at high and low temperature.

For selection purposes use can be made of the symmetry of the response curves, as genotypes adapted to a wide temperature range can generally be recognized by timely flowering at low temperature. However, selection at low temperature may include two response types illustrated in Fig. 4 that are less suitable as year-round cultivars:

- genotypes with a symmetric response curve but a low temperature optimum such as 'Helen' (flowering of those cultivars at high temperature is more likely to be inhibited);

- cultivars with a skewed response curve, showing rapid flowering at low temperatures and a severe delay at temperatures above the optimum.

The frequency of genotypes with these undesirable response types determines the efficiency of screening at low temperature for adaptation to a wide temperature range.

The cultivars used in this experiment were originally selected at different locations, generally at temperatures used in commercial ranges presumably near the optimum. No known selection pressure has so far been applied towards adaptation to low temperature and the results presented here may be considered a random sample of the temperature responses present in year-round chrysanthemums.

\section{Flower and spray quality}

The largest flowers were generally produced at the lower temperatures. Temperature also affected colour and shape of the petals. Generally the pigmentation of the pink or purple chrysanthemums was enhanced at low temperature which supported the observations of Stickland (1974). Formative effects of temperature were demonstrated in the cultivar 'Geisha' which turned from a pink spider at $14{ }^{\circ} \mathrm{C}$ to an almost white daisy type flower at $23^{\circ} \mathrm{C}$.

Temperature also affected the resumption of vegetative growth of the axillary buds which results in leafy flower sprays (a stem with flowering branches). This phenomenon occurred in those temperature-cultivar combinations in which flowering was delayed beyond about 80 days (see Table 2). This may suggest that the production of the flowering stimulus (stimuli) has to proceed at a certain minimal level; otherwise the conversion from the vegetative to the generative stage may slow 
down below a critical rate where renewed leaf production cannot any longer be suppressed. As shown in Table 2 a late cultivar such as 'Japanerin' throws leafy sprays at temperatures close to the optimum, while earlier cultivars have to be subjected to more extreme temperature conditions to slow down flowering beyond 80 days.

This also points to the use of rapidly flowering cultivars to avoid unsightly leaf production in the sprays under adverse conditions.

\section{Conclusions}

The optimum temperature for rapid flowering varies with cultivars. Most response curves resemble parabolas with fastest flowering at the optimum temperature and a similar delay in flowering at both higher and lower temperatures. Selection at the optimum temperature does not supply information on the time to flowering at higher or lower temperatures. For rapid flowering in year-round production seedlings should preferably be screened at the lowest temperature to be encountered in a year-round schedule.

\section{References}

Cathey, H. M., 1954a. Chrysanthemum temperature study. B. Thermal modifications of photoperiods previous to and after flower bud initiation. Proc. Am. Soc. hort. Sci. 64: 492-498.

Cathey, H. M., 1954b. Chrysanthemum temperature study. C. The effect of night, day and mean temperature upon the flowering of chrysanthemums. Proc. Am. Soc. hort. Sci. 64: 499-502.

Cathey, H. M., 1969. Chrysanthemum morifolium (Ramat.) Hemsl. In: L. T. Evans (Ed.), The induction of flowering, p. 268-290. MacMillan Company of Australia.

Cockshull, K. E., 1976. Flower and leaf initiation by Chrysanthemum morifolium Ramat in long days. J. hort. Sci. 51: 441-450.

Garner, W. W. \& H. A. Allard, 1920. Effect of the relative length of day and night and other factors of the environment on growth and reproduction in plants. J. agric. Res. 18: 553-606.

Hoeven, A. P. van der \& A. J. Vijverberg, 1977. Invloed van nachttemperatuur en onderbreking van de generative ontwikkeilng op groei en bloei bij chrysantencultivars. Bedrijfsontwikkeling 8: $183-187$.

Post, K., 1947. Year round chrysanthemum production. Proc. Am. Soc. hort. Sci. 49: 417-419.

Stickland, R. G., 1974. Pigment production by cultured florets of Chrysanthemum morifolium. Ann. Bot. 38: 1-6. 